\title{
Generalizing and Proving in an Elementary Mathematics Teacher Education Program: Moving Beyond Logic
}

\author{
Paul Weinberg ${ }^{1 *}$ \\ ${ }^{1}$ Oakland University, Rochester, Michigan, USA
}

Received 19 March 2018 - Revised 28 December 2018 - Accepted 20 January 2019

\begin{abstract}
Generalization and proof are a foundation of mathematical practice and as such should be integral to $\mathrm{K}-12$ mathematics instruction. However, if generalizing and proving are to become popular within $\mathrm{K}-12$ mathematics classrooms, we must consider how to effectively enlist pre-service teachers (PSTs) into supporting these activities in their prospective students. Some researchers have suggested that the major challenges to generalization and proving for students in mathematics lie in developing and explicating logical statements. These researchers indicate that children do not have access to these forms of reasoning until adolescence. Those holding such views typically do not advocate for the training of PSTs in elementary education to support mathematical generalizing and proving. This study characterizes the views of and engagement with mathematical generalizing and proving of those principally involved in elementary mathematics education: mathematics faculty, mathematics education faculty, and PSTs. These views and this engagement are analyzed from survey responses and participation in a problem-solving session. Few PSTs provided descriptions of proving as a generalized explanation and demonstrated explicit generalization and proving infrequently. The results suggest that a mathematical focus on logic may be an impediment to proving and generalizing.
\end{abstract}

Keywords: mathematics teacher education, elementary teacher education

\section{INTRODUCTION}

\section{Generalizing and Proving in K-12 Education}

Generalizing and proving are cornerstones of mathematical disciplinary practice and as such should be integral to K-12 mathematics instruction (Ball \& Bass, 2003; Hanna, 1991; 1995; Lakatos, 1976; Lehrer \& Lesh, 2003; NCTM, 1989; 2000). In spite of this, in the United States, mathematical proving is typically relegated to one semester of instruction in high school (traditionally within a geometry course) where this practice is developed in the form of the "two-column proof," a particular way of organizing a proof using two parallel columns that oftentimes prioritizes format over disciplinary argument (Herbst, 2002; Herbst \& Brach, 2006). Mathematical generalization is central to proving because it involves what Stylianides (2007a) refers to as the "formulation" of the proof. The generalization supports the argument that some property or technique holds for all mathematical objects or conditions. Accordingly, the scope of the claim is always larger than the set of individually verified cases; typically, it involves an infinite number of cases (e.g., for all integers). Supporting mathematical proof and generalization has been endorsed by the Common Core State Standards for Mathematics (National Governors Association Center for Best Practices \& Council of Chief State School Officers [NGA \& CCSSO], 2010) and the National Council of Teachers of Mathematics $(1989,2000)$.

(C) 2019 by the authors; licensee Modestum Ltd., UK. This article is an open access article distributed under the terms and conditions of the Creative Commons Attribution License (http://creativecommons.org/licenses/by/4.0/). \weinberg@oakland.edu (*Correspondence) 


\section{Contribution of this paper to the literature}

- Provides the perspective that a focus on disciplinary practices, without a consideration of formal logic, is important within elementary mathematics teacher education programs (both in methods and content courses).

- Investigates the propensity of mathematicians, mathematics educators, and pre-service elementary teachers (within a elementary mathematics teacher education program) to engage in disciplinary practices (e.g., generalizing, proving).

- Considers that a focus on standard logic, within elementary mathematics teacher education, may be an impediment to a focus on generalizing and proving.

\section{Generalizing and Proving with Logic}

College undergraduates in elementary mathematics teacher education programs must develop the capacities to engage their prospective students in proving (Stylianides \& Ball, 2008; Stylianides, Stylianides, \& Philippou, 2007). Selden and Selden (1995) highlight a popular view that pre-service teachers (PSTs) in elementary mathematics education be able to "determine the logical structure of informal mathematical statements" (p. 127) (e.g., if p then $q$ implies that $\mathrm{p}$, then $\mathrm{q}$ ). They note that students who cannot explicate logical statements "often can neither ask nor adequately answer...[mathematical] questions [through proofs]." (p. 127) This framing of proving highlights the logical format of the proof over the content. In addition, it emphasizes the value of unpacking and developing statements using logic, rather than through informal statements within mathematical arguments. Piaget (1958) and mathematics educators (e.g., van Hiele, 1986; Burger \& Shaughnessy, 1986) have indicated that children do not have access to these forms of reasoning until adolescence, based on research conducted using logic.

Supporting generalization and proving with logic relies upon domain-general theories of knowledge development. (Schauble, 1996; Schauble, Glaser, Duschl, Schulze, \& John, 1995) Domain-general theories argue that individuals develop global knowledge structures that contain cohesive, whole, and widely applicable knowledge. However, domain-specific models argue that many aspects of cognition are supported by specialized learning structures. Thus, using conditional implication inference (Byrnes \& Overton, 1988; Inhelder \& Piaget, 2013; Ward \& Overton, 1990) (domain-general knowledge), a competency in logic that is not specific to mathematics, is very different from engaging in mathematical proving and generalizing about a specific mathematical problem (domainspecific knowledge) (e.g., why does the decimal representation of $\frac{1}{3}$ repeat). This is why logic is limited as requisite knowledge for generalization and proof.

\section{Generalizing and Proving within Mathematics}

A view of mathematical generalizing and proving based on competencies in logic are not universally accepted within mathematics education (e.g., Carpenter, Franke, Levi, 2003; Jeannotte \& Kieran, 2017); however, these views are popular and an impediment to the development of an individual's generalizing and proving. Kilpatrick, Swafford, and Findell (2001) advocated a shift to a view of mathematics that supports participation in disciplinary practices of knowledge creation and revision, such as generalizing and proving. Lehrer and Lesh (2003) propose the means to support a disciplinary perspective in mathematics that does not rely on competencies from logic; they describe this as a genetic view of mathematical learning. For example, Barkai, Tsamir, Tirosh and Dreyfus (2002) indicate that generating informal statements and mathematical arguments, without a reliance on logic, is necessary for teachers to support mathematical learning in elementary schools. Lehrer and Lesh argue that the competencies to engage in proving are built from our cultural familiarity with contesting claims from very young ages; moreover, they claim that these early competencies must be developed in mathematically specific contexts. In addition, Stylianides (2007a) does not conceive of proving as an activity that demands logical constructions; rather, proving leverages cultural competencies that must be mathematized through appropriate training over time. Stylianides (2007c) enumerates four major elements of an argument that are important to consider when deciding whether an argument qualifies as a proof: “... the argument's foundation (i.e., what constitutes its basis: definitions, axioms, etc.), formulation (i.e., how it is developed: as a logical deduction, as a generalization from particular cases, etc.), representation (i.e., how it is expressed: using everyday language, algebraically, etc.), and social dimension (i.e., how it plays out in the social context of the community wherein it is created)." (p. 2) Accordingly, the logical deduction element is only present (if at all) as part of the proof's format. Although Stylianides presents these criteria for proofs, within elementary education, he presents a means to consider these criteria across all levels of mathematical education (including mathematics teacher education). In addition, Stylianides presents what he refers to as the intellectual-honesty and continuity principles. 
Table 1. Participants

\begin{tabular}{lcc}
\hline Participants & Total Number Included in Analysis & Number Included in Video Analysis \\
\hline Pre-service Teachers & $69($ female $=59)$ & $14($ female $=8)$ \\
\hline Mathematics Faculty & $6($ female $=2)$ & $6($ female $=2)$ \\
\hline Mathematics Education Faculty & $5($ female $=3)$ & $4($ female $=3)$ \\
\hline
\end{tabular}

\section{Generalizing and Proving in an Elementary Teacher Education Program}

The intellectual-honesty principle states that the notion of proof in school mathematics should be conceptualized so that it is honest to mathematics as a discipline and honors students as mathematical learners (Sylianides, 2007b; 2007c). The continuum principle states that there should be continuity in how the notion of proof is conceptualized in different grade levels so that students' experiences with proof in school have coherence. Although these constructs were developed to analyze proving in elementary education, they also can be applied to elementary teacher education. Accordingly, what constitutes a proof in mathematical professional practice is different from that for mathematics faculty, mathematics education, and PSTs working within an elementary mathematics teacher education program. For example, the problem "Why does $\frac{1}{7}$ repeat" would be trivial for a professional mathematician; this problem would appear specific and not warrant a proof. However, this problem is useful for those within a mathematics elementary teacher education program (e.g., mathematics faculty, mathematics education faculty, PSTs) because it has the potential to support the following criteria of a proof: formulation (e.g., how one draws upon this this specific problem and generalizes across all rational numbers) and representation (decimal representations of rational numbers and how these representations terminate or repeat). The expectation should be that all members within an elementary mathematics teacher education program should engage with proof with similar intellectual-honesty and at a similar location along the continuum of mathematical proof.

This study focuses on the propensity for mathematics faculty, mathematics education faculty, and PSTs to consider and engage in generalization and proving according to Sylianides' (2017c) definition, based on the development of specific mathematical practices and knowledge and not as a consequence of competencies in logic. While there have been studies that look at the need to support generalizing and proving in the K-12 classroom and in elementary methods courses (Ball \& Bass, 2003; Ball \& Cohen, 1999; Ellis, 2011; Stylianides, 2007a; 2007b), this work addresses how conceptions of proving (disciplinary or logic-based) impact the generalizing and proving that is engaged in by the principal players within an elementary mathematics teacher education program, those responsible for the collaborative development of these mathematical practices. Through survey responses, participants described their conceptions of proofs and proving. Within a problem-solving session, participants were given the opportunity to generalize and prove, within the mathematical subdomain of number theory. Number theory (a branch of mathematics devoted to the study of natural numbers, integers, and rational numbers) is critical to understanding mathematics across the grades.

\section{Research Questions}

This study investigates how mathematics and mathematics education faculty develop mathematical practices within PSTs. The research questions the study investigates are: (1) how do mathematics faculty, mathematics education faculty, and PSTs in elementary education view proofs and proving and their relationship to standard logic and (2) to what extent do mathematics faculty, mathematics education faculty, and PSTs in elementary education show the propensity to prove and generalize without the use of generic logical structures?

\section{METHODS}

\section{Participants}

Study participants included mathematics faculty, mathematics education faculty, and PSTs (Table 1) from a public college in the Midwestern United States. All participants were members of the elementary education program as faculty or students. The elementary teacher education program at this university is similar to many undergraduate elementary education programs across the country. PSTs are required to take courses within the school of education and college of arts and sciences. Within the school of education, PSTs take mathematics methods courses taught by mathematics education faculty. Within the college of arts and sciences, PSTs take mathematics content courses (e.g., numerical structures) taught by mathematics faculty.

In this study, all mathematics faculty $(n=6)$ were included in the video-recorded problem-solving sessions. All but one mathematics education faculty $(n=5)$ was included in the video-recorded problem-solving sessions. This 
faculty member indicated that he was not comfortable being recorded. The PSTs were recruited from the elementary education program's mathematics education courses (these courses only enrolled elementary education majors). Of the PSTs who completed the surveys $(n=69)$, fourteen agreed to participate in a video-recorded problem-solving session.

\section{Instruments}

Surveys. The survey, presented to students in a Google Form, assessed participant conceptions of proof and proving. The survey consisted of three questions (Appendix A): "What is the purpose of proving in mathematics;" "What different ideas might students have about what it means for something to be true for all cases in mathematics;" "Give an example of how proof was used in a mathematics course you taught/took."

Problem-solving session. The tasks used during the problem-solving sessions (Appendix B) were developed to instigate and support participants to engage in mathematical generalizing and proving in a manner that was intellectually-honest and at an appropriate location within the continuum of proof (Stylianides, 2017c). Two of these tasks were taken from the mathematics education literature that focuses on these mathematical practices (Appendix A) (\#5, Zazkis, 2005; \#10, Zazkis \& Sirotic, 2004). These thirteen tasks were presented to all participants on participant worksheets; each question was also read aloud by the researcher. Mathematics faculty might not typically use generalization or proof to solve these problems. However, the expectation was that PSTs as well as mathematicians and mathematics education faculty, within an elementary mathematics teacher education program, would be able to find means to meaningfully explain and justify these problems by applying generalization and proof. For example, one problem asks "How do you know whether a decimal will repeat or terminate?" This problem is trivial to a mathematics professor. However, within an elementary mathematics teacher education program there is significant intellectually-honest mathematical generalization and proof that can and should be provided by mathematics faculty, mathematics education faculty, and PSTs. For example, these three groups could be expected to start with a specific example (e.g., why does the decimal representation of $\frac{2}{5}$ terminate while that of $\frac{2}{3}$ repeats?). Each group may then provide a general case (e.g., why do all fractions with denominators that divide powers of 10, terminate?) The explanations of these questions could easily be generalized and proven in a manner that would satisfy Sylianides four criteria of proof. This study focused on the particular episodes of proving that participants engaged in through their informal mathematical explanations.

\section{Procedure}

Surveys. The researchers administered surveys in four classes for undergraduate elementary education majors with mathematics endorsements (areas of focus). These surveys were administered through Google Forms. Emails with links to these Google Forms were sent to all students through the courses' Moodle sites. These surveys targeted participant views of mathematical proving. Eighty participants were given access to and completed the surveys (Appendix A). These participants were given twenty minutes to complete the surveys.

Problem-solving sessions. The researchers conducted 24 problems-solving sessions. These problem-solving sessions were video-recorded and then digitally rendered. Each of 24 participants individually took part in one of these sessions, working on mathematical tasks, in collaboration with researchers (one PST in elementary education and one mathematics education faculty/the author) about numerical structures. Thirteen problems (Appendix B) were presented within these problem-solving sessions. These sessions were structured to encourage informal mathematical explanation and discourage formal mathematical proofs, within traditional logic structures. Participants were encouraged to provide explanations of their solutions; however, they were never explicitly told to generalize or prove; this choice was made to investigate participant natural propensity to construct mathematical explanations. Further, this setup was chosen to avoid placing participants (especially PSTs) under undue pressure to construct known proof formats (or proofs at all). These problem-solving sessions were framed as opportunities for respondents to think through problems and their solutions. The researchers encouraged participants to "do your best," stating that, "there are no right or wrong answers; we are simply interested in how you think about and explain these problems." Accordingly, participants were frequently reminded to think-aloud as they solved each problem. Participants were given as long as they needed to work through and explain all problems in the problemsolving sessions. The problem-solving sessions ranged from 30 to 72 minutes (Mean $=43$ mins).

\section{Analysis}

To assess participant conceptions and enactments of mathematical generalizing and proving, coding schemes were developed for the surveys and problem-solving sessions.

Surveys. Two researchers analyzed one of the survey questions ("What is the purpose of proving in mathematics?") according to a coding document (Appendix C). This coding document characterizes participant 
conceptions of proving according to how they understand the limitations of empirical argument within proving (e.g., Stylianides \& Stylianides, 2009), with the second coding category specifically informed by Chazan (1993). Participant responses to these questions were coded into the following categories.

1. Does not address ideas in mathematical proving.

2. Mathematical proving based on a single example. Participant indicates proving provides justification for only a limited number of cases.

3. Solving a mathematical question with finite cases. Participant explains a class or property of a class by citing a limited number of examples.

4. Solving a mathematical question for all cases. Participant explains a class or property of a class by citing general properties (or relations between properties) of that class.

The following three survey questions ("What is the purpose of proving in mathematics;" "What different ideas might students have about what it means for something to be true for all cases in mathematics;" "Give an example of how proof was used in a mathematics course you taught/took?") were scored dichotomously along one dimension. These questions were scored according to the presence or absence of language related to logic (e.g., "students must be able to understand and use logical connectives") and indications that mathematical generalizing and/or proving is age dependent (e.g., "students must have entered Piaget's formal operations stage"). This determined whether participants had a propensity to describe proving as based on logic, rather than as supporting student mathematical development and disciplinary practices (e.g., generalizing, proving). Two researchers were trained with this coding scheme. These researchers analyzed 80 survey responses. The inter-rater agreement was $92 \%$.

Problem-solving session. Two researchers coded generalization and proving within participant problemsolving sessions according to an analytic framework (Appendix D). Mathematical generalization was coded based on the following scheme, developed according to Lerher, Kobiela, and Weinberg (2013). This framework characterizes generalization as a disciplinary practice within mathematics and not a competency requiring general logic.

1. No generalization. Participant refers to a specific mathematical object, measure, property, or computational product.

2. Implicit generalization. Participant refers to a specific mathematical object, measure or property, but implicitly represents or easily affords a generalization.

3. Explicit generalization. Explicit reference to a mathematical class, such as 'irrational numbers,' or to a property of a class, such as the 'area of triangles.'

Mathematical proving was coded according to the following scheme (Appendix D), developed according to Balacheff (1988). This framework was developed to characterize the practice of proving and not logical competencies.

1. No proving.

2. Naïve empiricism. Participant asserts the validity of a mathematical result after confirming a finite number of cases.

3. Generic example. Participant makes the reasons for the truth of a mathematical assertion explicit by means of operations or transformations on an object that is not there in its own right, but as a characteristic representative of its class.

4. Thought experiment. Participant indicates a generic example. In addition, participant constructs an anecdotal temporal development, where the mathematical operations and foundational relations are indicated in some other way than by the result of their use.

A participant's work on one mathematical problem was defined as an instance. All instances were coded using NVivo 10.0 software. There were 575 instances. Two researchers were trained on this coding scheme. The interrater reliability between these two researchers was $86 \%$ for the problem-solving sessions.

One-tailed Mann-Whitney U tests were conducted to compare the difference in rank-ordered scores for generalization and proving between mathematics and mathematics education faculty as well as between faculty (mathematics education and mathematics) and PSTs. The one-tailed Mann-Whitney U tests were conducted because ordinal data was used to score participant explanations for generalizations and proofs.

Analyzing mathematical arguments. Finally, the mathematical arguments constructed by two participants, from the problem-solving session, are characterized according to the analytic frameworks for generalizing and proving. This comparison looks at explanations from a mathematics faculty member and a PST, each solving the same problem. The following question was posed to these participants: "Consider $\frac{1}{3}$, which can be written as the following repeating decimal $0 . \overline{3}=0.33333 \ldots$ Explain why this decimal repeats?" This problem was intended to 
Table 2. Survey response percentages

\begin{tabular}{lccc}
\hline $\begin{array}{l}\text { What is the purpose of proving in } \\
\text { mathematics? }\end{array}$ & $\begin{array}{c}\text { Mathematics Faculty } \\
\mathbf{N}=\mathbf{6}\end{array}$ & $\begin{array}{c}\text { Mathematics Education Faculty } \\
\mathbf{N}=\mathbf{5}\end{array}$ & $\begin{array}{c}\text { Pre-service Teachers } \\
\mathbf{N}=\mathbf{6 9}\end{array}$ \\
\hline Does not address ideas in proving & $0 \%(0)$ & $0 \%(0)$ & $70 \%(48)$ \\
\hline $\begin{array}{l}\text { The deductive proving was for a single } \\
\text { example. }\end{array}$ & $0 \%(0)$ & $0 \%(0)$ & $19 \%(13)$ \\
\hline Solving a question with finite case(s). & $0 \%(0)$ & $0 \%(0)$ & $4 \%(3)$ \\
\hline Solving a question for all cases & $100 \%(6)$ & $100 \%(5)$ & $7 \%(5)$ \\
\hline
\end{tabular}

Table 3. Coding of survey response language related to logic and age dependency

\begin{tabular}{lccc}
\hline & Mathematics Faculty & Mathematics Education Faculty & PSTs \\
\hline Language Related to Logic & $3(50 \%)$ & $1(20 \%)$ & $10(13 \%)$ \\
\hline $\begin{array}{l}\text { Language Related to Age Dependency } \\
\text { Knowledge (Focus on Disciplinary Practices) }\end{array}$ & $3(50 \%)$ & $0(0 \%)$ & $16(23 \%)$ \\
\hline No Experience with Proving. & $2(33 \%)$ & $4(80 \%)$ & $35(51 \%)$ \\
\hline
\end{tabular}

support mathematical explanation and provide opportunities for generalizing and proving. These participants were chosen for comparison because, on the surface, they provided similar explanations by initially approaching the question by appealing to the division process.

\section{RESULTS}

This section describes participant views of and engagement with mathematical generalizing and proving from survey results and problem-solving sessions. In addition, mathematical explanations (within those problemsolving sessions) from mathematics faculty and a PST are analyzed and described in greater detail.

\section{Views of Proving}

Mathematicians. When responding to the survey question, "What is the purpose of proving in mathematics," $100 \%(n=6)$ (Table 2; Appendix C) of mathematics faculty provided responses that indicated an understanding that mathematical proving involves solving a mathematical question for all cases. One mathematics faculty described the purpose of proving in the following way: "[The goal of proving is] to know that a conjecture is actually true for all cases."

In the survey responses (Table 3), three (50\%) mathematics faculty indicated that proving in mathematics required competencies in logic. For example, one mathematician commented that proving requires a student to "[c]onvince another...of the truth value of a statement effectively employing aspects of conditional implication inference." In addition, three mathematics faculty (50\%) indicated that they believed proving was age dependent. For example, "Proving should come in the last three years of high school. Proving can lead to frustration if a student is not mentally prepared for it."

Mathematics educators. One hundred percent $(n=5)$ of mathematics education faculty also described proving as solving a mathematical question for all cases (Table 2). One participant responded: "Proving is about ... knowing for sure that something is true (it's more than thinking something is probably true because it appears to be). When you've proven something, you know for sure it is true. It's also about generalization - it's more than proving that a specific situation is true; it's about proving that some statement is always true (or always false)."

One mathematics educator (20\%) described logic as related to mathematical proving. For example, she noted, "[The role of proving is] to use rules of logic to provide justification that a statement is true." In addition, this participant referenced "logical connectives" and "truth-values," indicating the belief that mathematical proof has general logic as a format and foundation. No mathematics educators suggested that proving was age dependent.

Pre-service teachers. Only 7\% $(\mathrm{n}=5)$ of PSTs described the purpose of proving as solving a mathematical question for all cases. For instance, one student noted: "The purpose of proving in mathematics is showing why something works and that it will always work because of an understanding of the pattern...If you understand how a pattern works, you can explain what you will get for the first term and the $\mathrm{n}^{\text {th }}$ term." In addition, $62 \%(\mathrm{n}=48)$ did not attend to ideas within proving. One PST wrote, "[The role of proof is to] ...check your work."

In the survey responses (Table 3), ten (14\%) PSTs indicated that proving in mathematics required competencies in logic. In addition, 16 PSTs (23\%) indicated that they believed proving was age dependent. For example, one PST stated the following, "In my learning theories class I learned that proving could be damaging to ... young children because they would be unable to master the logic." In addition, 21 (38\%) PSTs indicated that they either had not 
Table 4. Generalizing and proving by instance

\begin{tabular}{|c|c|c|c|}
\hline Coding Categories & Numerical Codes† & $\begin{array}{c}\text { Faculty } \\
N=200 \text { instances }\end{array}$ & $\begin{array}{c}\text { Pre-service Teachers } \\
\mathbf{N}=375 \text { instances }\end{array}$ \\
\hline Generalizing & & $n=102$ & $n=177$ \\
\hline No generalization & 1 & $40 \%(41)$ & $69 \%(122)$ \\
\hline Implicit & 2 & $25 \%(26)$ & $15 \%(27)$ \\
\hline Explicit & 3 & $34 \%(35)$ & $16 \%(28)$ \\
\hline Proving & & $n=98$ & $n=198$ \\
\hline No proving & 1 & $81 \%(80)$ & $88 \%(174)$ \\
\hline Naïve Empiricism & 2 & $8 \%(6)$ & $9 \%(18)$ \\
\hline Generic Example & 3 & $4 \%(4)$ & $3 \%(5)$ \\
\hline Thought Experiment & 4 & $8 \%(8)$ & $1 \%(1)$ \\
\hline
\end{tabular}

had any experience with mathematical proving in their undergraduate mathematics courses or if they had, they did not remember it.

This section shows that mathematics and mathematics education faculty understand that proving requires generalizing. However, PSTs infrequently made this connection. In addition, 50\% of mathematics faculty indicated a belief that logic is essential to proving and that proving is age-dependent. Mathematics education faculty less frequently indicated this belief.

\section{Proving and Generalizing without the use of Logic}

Within these problem-solving sessions, participants were encouraged to develop mathematical explanations. Mathematics and mathematics education faculty demonstrated similar competencies with generalizing and proving in problem-solving contexts. In addition, PSTs showed a proclivity to engage with these practices (Table 3), but with limited frequency. Because participants were not asked to prove or generalize, many participants may not have made efforts to provide proofs and generalization on every (or any) instance(s). Thus, this section does not characterize whether a participant is capable of providing a proof or generalization; rather, it provides an indication of those participants who were so inclined when provided with opportunities.

Generalizing. Mathematics faculty demonstrated explicit generalization in 32\% ( $\mathrm{n}=24)$ of instances, while mathematics education faculty demonstrated this practice in $41 \%(n=11)$ of instances. In $16 \%(n=28)$ of instances PSTs demonstrated explicit generalization (Table 3).

There is no difference between the overall rank-ordered score for generalization between mathematics (Table 3) and mathematics education faculty $(U=830.5$, Mann-Whitney $U$ test). However, when combined into one category (i.e., faculty), mathematics and mathematics education faculty $\left(U_{1}\right)$ showed a difference in rank-ordered score from the PSTs $\left(U_{2}\right)\left(U_{1}>U_{2}, U=6325, p<0.00001\right.$, Mann-Whitney U test) (Table 4). All mathematics and mathematics education faculty members scored at the highest level of generalization on at least one instance. However, only three PSTs (21\% of instances) scored at the highest level of generalization on at least one instance. None of the participants coded at the levels of implicit and explicit generalization presented their mathematical arguments within traditional logical structures.

Proving. Mathematics faculty demonstrated proving (i.e., generic example and thought experiment) in $11 \%$ (n $=8$ ) of instances, while mathematics education faculty demonstrated these practices in $17 \%(n=4)$ of instances. However, only one PST demonstrated these highest levels of proving (Table 3).

Mathematics faculty $\left(U_{1}\right)$ showed higher rank-ordered scores then mathematics education faculty $\left(U_{2}\right)\left(U_{1}>U_{2}\right.$, $\mathrm{U}=882, \mathrm{p}<0.05$, Mann-Whitney $\mathrm{U}$ test) (Table 3). In addition, both mathematics and mathematics education faculty showed a difference in rank-ordered scores from the PSTs $(U=1.16, p<0.00001$, Mann-Whitney U test). None of the participants coded at the levels of naïve empiricism, generic example, or thought example presented their proofs within traditional logical structures.

This section indicates that mathematics and mathematics education faculty show important competencies in generalization; however, the Mann-Whitney $U$ test shows that mathematics faculty show greater proficiency in proving than mathematics education faculty. This demonstrates the competencies in generalization and proving of those faculty (mathematics and mathematics education) responsible for developing disciplinary knowledge within PSTs. Moreover, these analyses show that PSTs show less propensity to engage in these disciplinary practices than faculty. 
Problem-Solving Session Code: Generalization: Explicit Generalization; Proving: Generic Example

John: Well, one way to think about $\frac{1}{3}$ is (.) it's the result of dividing 1 by 3 ...and if you

carry out that operation, with the usual algorithms for dividing decimals, you get $0 . \overline{3}$ as you carry out the algorithm, you keep getting a remainder of one and so it never terminates...

...going back to your original question of why that $\left[\frac{1}{3}\right]$ repeats... another way of thinking about the answer to that question is if it's not going to repeat than we're going to have to rewrite $\frac{1}{3}$ as some whole number in the numerator with a power of 10 in the denominator...

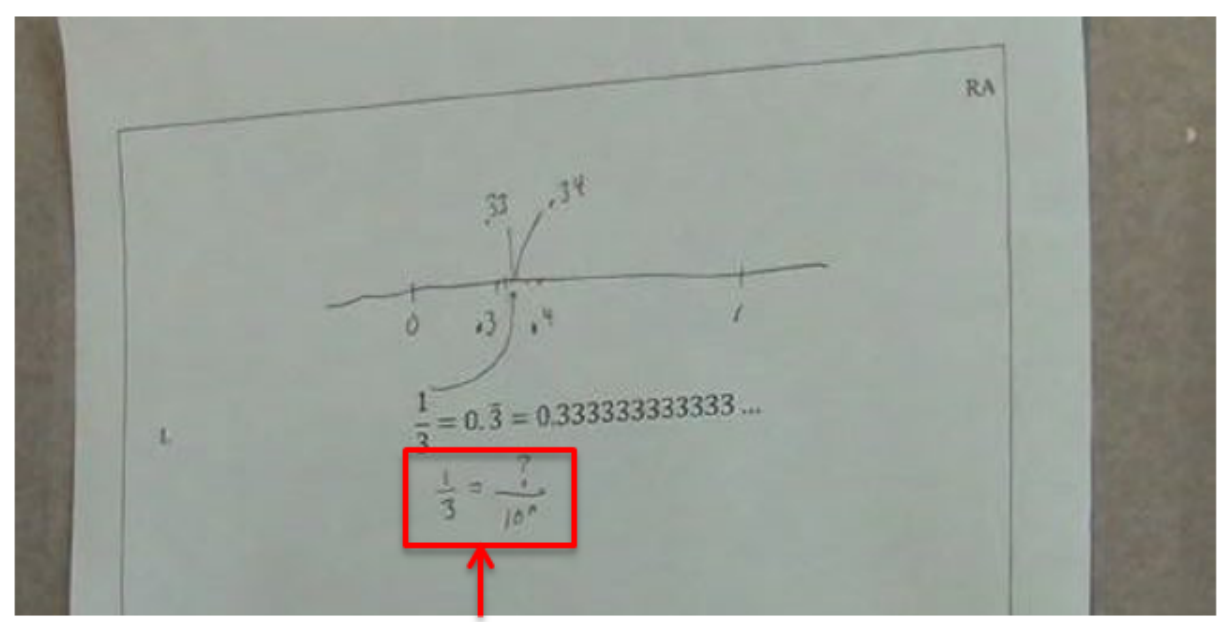

"if it's not going to repeat than we're going to have to rewrite $\frac{1}{3}$ as some whole number in the numerator with a power of 10 in the denominator..."

...And (.) because of a number of number theoretic facts about how fractions work, that can't be done. The fundamental law of fractions says the only way [this decimal representation of $\frac{1}{3}$ will terminate] is if 3 times something is a $10^{\mathrm{n}}$ th power and because of the unique factorization of $10^{\mathrm{n}}$ th powers, it won't. This is what the fundamental theorem of arithmetic tells us.

Figure 1. Mathematics faculty (John) engages in generalizing and proving in his explanation

\section{Considering Mathematical Argument from a Disciplinary Perspective}

Arguments made by a mathematics faculty member and a PST are compared to further analyze participant propensity to generalize and prove. These arguments present examples of proofs that are made without logical structures. This comparison looks at explanations from these two participants as they solved the same mathematical problem. The following question was posed to these participants: "Consider $\frac{1}{3}$, which can be written as the following repeating decimal $0 . \overline{3}=0.33333$... Explain why this decimal repeats." This problem (Appendix B, problem 1) was included to support mathematical explanation and provide opportunities for generalizing and proving. These participants were chosen because their explanations were similar in that these participants approached the question by appealing to the division process; they were also coded the same. In addition, they represented the thinking of an expert (mathematics faculty) and novice (PST).

John (mathematics faculty) (Figure 1) was coded at the level of generic example (Appendix D). He began his argument by stating: “ $\ldots \frac{1}{3}$ is (.1) it's the result of dividing 1 by $3 . .$. and if you carry out that operation, you get $0.333 \ldots$ 
as you carry out the algorithm, you keep getting a remainder of one and so it never terminates." Then, John made use of operations on a generic example (an element in the set of rational numbers). For example, to explain why the decimal representation of $\frac{1}{3}$ does not terminate, John presented an argument that relied upon the fundamental law of fractions and the fundamental theorem of arithmetic: "The fundamental law of fractions says the only way [a decimal representation of] a fraction with 3 as a denominator will terminate is if 3 times something is a $10^{\text {nth }}$ power and because of the unique factorization of $10^{\text {nth }}$ powers, it won't [be]. This is what the fundamental theorem of arithmetic tells us." In addition, John was coded as engaging in explicit generalization. Thus, John provided an explanation of what causes $\frac{1}{3}$ to repeat by addressing why all decimal representations of fractions with three in the denominator repeat.

Jessica, a PST, presented an explanation that was coded at the levels of generic example and explicit generalization. Jessica was the only PST coded at explicit generalization. She provided this explicit generalization in response to the question about why $\frac{1}{3}$ repeats.

Jessica: I know it repeats because [when I divide 3 into 1, 3 is] never going to go into 10 evenly, [we will continue to get 1 as a remainder]...So, all we add are zeros [and the remainder will repeat]?

ES: How do you know whether a decimal will repeat or terminate? So, if you were to look at those fractions, $\frac{1}{6}$ vs. $\frac{3}{4}$, could you tell if it repeats or terminates.

Jessica: ... Okay, so if we look at $\frac{1}{6}$, we're doing 6 into 1 . So, we know [the first digit in the quotient is] 0 and then (dividing 6 into 1 using the standard division algorithm) we have all of these other 0s [to bring down]. (She then calculates the decimal representation of $\frac{1}{6}$ on her calculator) So, everyone knows that $\frac{3}{4}$ is 0.75 , but I mean if they're different fractions, like not $\frac{3}{4}$ I don't know if by looking at it if I would know that it repeats. Well, like $\frac{1}{2}$ obviously doesn't repeat. And we know $\frac{1}{3}$ does. $\frac{1}{4}$ doesn't. $\frac{1}{5}$ doesn't. Well $\frac{1}{3}$ does and $\frac{1}{6}$ does. So, maybe like the multiples of 3 [are meaningful]. So, maybe if a multiple of 3 is on the bottom and a one is on the top. So, like $\frac{1}{3}$ did [repeat], $\frac{1}{6}$ did [repeat]. So, I guess, okay maybe okay $\frac{1}{9}, \frac{1}{12}$ [both repeat]. So, ...if [the denominator is] a multiple of 3 , with a one [in the numerator], [the fraction] repeats.

Thus far, Jessica has provided a generalization. Now, the interviewer (ES) provides Jessica with a probe that supports her to connect this generalization to a larger argument, a generic example.

ES: You just made a conjecture. You have claimed that all fractions with numerators of one and multiples of three in the denominator will repeat. Why is it that... $\frac{1}{3}, \frac{1}{6}, \frac{1}{9}$, and $\frac{1}{12}$ repeat? Why won't multiples of 3 go into powers of 10 ?

Jessica: There's ... always going to be a remainder. 3 won't go into 10 and 6 won't go into 10 and 9 and 12 won't go into 10 because... This is because the 3 won't go into 10 or 100 or 1,000 or 10,000. 3 just won't go into...p powers of 10 .

Jessica makes the following explicit generalization: "So, ...if [the denominator is] a multiple of 3, with a one [in the numerator], [the fraction] repeats." Then, Jessica uses this generalization to construct a generic example. To make her argument about why decimal representations of fractions repeat, she elaborates on her four thoughtfully chosen generic examples $\left(\frac{1}{3}, \frac{1}{6}, \frac{1}{9}\right.$, and $\left.\frac{1}{12}\right)$. Jessica argues that " 3 won't go into 10 and 6 won't go into 10 and 9 and 12 won't go into 10 because...the 3 won't go into 10 or 100 or 1,000 or 10,000. 3 just won't go into...powers of $10 . "$ This example implicitly represents these four cases, but explicitly represents an argument about a broader class of mathematical objects (fractions whose decimal representations repeat).

\section{DISCUSSION}

\section{Participants Views of Proving (Survey Results)}

Through the analysis of survey data, mathematics and mathematics education faculty described proving as solving a question for all cases. However, only 6\% of PSTs provided similar descriptions (Table 2). Some 
mathematics and mathematics education faculty indicated that logic was required for the development of these practices. For example, $50 \%(n=3)$ of mathematicians and $20 \%(n=1)$ of mathematics educators described generalizing and proving in terms of logic. It is interesting to note that such descriptions were seen in $13 \%(n=10)$ of PSTs. This suggests that mathematics and mathematics education faculty, to some extent, may be contributing to this view. Thus, an important element in the development of generalizing and proving in PSTs seems to be how mathematics and mathematics education faculty view the means to support these practices. Accordingly, the domain-general principles of logic do not support individuals to engage in generalization and proving (Barkai, Tsamir, Tirosh \& Dreyfus, 2002; Lehrer \& Lesh, 2003; Stylianides 2007a, 2007b, 2007c), which are practices that are specific to (and situated within) mathematics contexts.

\section{Participant Proving Practices (Problem-Solving Sessions)}

In the problem-solving sessions, mathematics and mathematics education faculty demonstrated explicit generalization similarly often. However, PSTs demonstrated explicit generalization infrequently (16\%) (Table 3). Moreover, the Mann-Whitney U test shows that faculty have a propensity to display greater proficiency in proving than the PSTs; these interns demonstrated the highest levels of proving infrequently (4\%) (Table 3 ). This is not surprising because proving is virtually absent from K-12 mathematics instruction (Herbst, 2002; Herbst \& Brach, 2006) and largely absent from undergraduate mathematics elementary education courses (Stylianides, Stylianides, \& Phillipou, 2007). For instance, while proving is central to the university mathematics curriculum, many undergraduate students lack an understanding of it (Dubinsky, 1986, 1990; Dubinsky \& Lewin, 1986; Harel, 2002; Knuth, 2002; Movshovitz-Hadar, 1993).

\section{How do Participants Prove and Generalize, without the use of Logic?}

None of the mathematical arguments made by participants were structured using the logic of traditional proofs. This is an indication that the early resources for generalizing and proving are present within PSTs and must be leveraged (Lehrer \& Lesh, 2003). Jessica's argument within the problem-solving session shows that she is generalizing and proving at the same level as John, with some support from the interviewer. In addition, 30\% ( $\mathrm{n}=$ 21) of PSTs indicated some understanding of proving on the surveys. Moreover, in problem-solving sessions PSTs engaged in some degree of mathematical generalizing ( $31 \%, n=55$ instances) and proving (13\%, $n=24$ instances). Thus, these resources are present and available; however, they must be developed in order for these PSTs to have the proclivity to engage their K-12 students in these mathematical practices.

These findings reinforce the notion that in order to develop generalization and proof, students must be exposed to these domain-specific practices. It is problematic that $26 \%$ of PSTs indicated that they either had not had any experience with mathematical proving in their undergraduate mathematics courses or they did not remember it. If students are barely exposed to generalizing and proving in their K-12 education, they must have opportunities to develop these practices within their college undergraduate training in both mathematics content and methods courses. It is likely that the faculty focus on logic and minimal student exposure to these disciplinary practices accounts for the poor performance of PSTs in proving. However, because all mathematics and mathematics education faculty were assessed at the highest levels of generalization and proving, these resources could (and should) be appropriated. Thus, generalizing and proving must be systematically taught within the undergraduate curriculum.

\section{How can a Disciplinary Perspective Support Mathematical Argument?}

This study investigates mathematical generalizing and proving from a disciplinary practice-based perspective (Lehrer \& Lesh, 2003), without a focus on logic. Instead of relying on logic, this perspective considers the domainspecific resources that participants have for generalizing and proving. Logic uses modus ponens, modus tollens, and conditional implication inference to assess the capacity to generalize or prove; however, these tests of logic are peripheral to what is required to engage in these mathematical practices. In order to support mathematical generalizing and proving it is necessary to support these practices within mathematical contexts and not through domain-general competencies. Thus, it is not as important to be able to reason generally (as logic demands); it is important to be able to reason about specific mathematical problems (e.g., "Why does $\frac{1}{3}$ repeat").

\section{Next Steps}

Additional studies should be conducted to further investigate how elementary mathematics teacher education programs are and can be supported to develop generalizing and proving within their PSTs. Mathematics content and methods courses can no longer shy away from these necessary disciplinary practices. A recent focus in teacher education programs has been on domain-general "high leverage teaching" practices (Ball \& Forzani, 2011). These 
practices are important; however, mathematics teacher education programs must not lose sight of the mathematicsspecific practices that are central to supporting mathematical learning.

\section{REFERENCES}

Balacheff, N. (1988). Aspects of proof in pupils' practice of school mathematics. Mathematics, teachers and children, 216, 235.

Ball, D. L., \& Bass, H. (2003). Making mathematics reasonable in school. A research companion to principles and standards for school mathematics, 27-44.

Ball, D. L., \& Cohen, D. K. (1999). Developing practice, developing practitioners: Toward a practice-based theory of professional education. Teaching as the learning profession: Handbook of policy and practice, 1, 3-22.

Ball, D. L., \& Forzani, F. M. (2011). Building a common core for learning to teach: And Connecting professional learning to practice. American educator, 35(2), 17.

Barkai, R., Tsamir, P., Tirosh, D., \& Dreyfus, T. (2002). Proving or Refuting Arithmetic Claims: The Case of Elementary School Teachers.

Burger, W. F., \& Shaughnessy, J. M. (1986). Characterizing the van Hiele levels of development in geometry. Journal for research in mathematics education, 31-48. https:/ / doi.org/10.2307/749317

Byrnes, J. P., \& Overton, W. F. (1988). Reasoning about logical connectives: A developmental analysis. Journal of Experimental Child Psychology, 46(2), 194-218. https:/ / doi.org/10.1016/0022-0965(88)90057-4

Carpenter, T. P., Franke, M. L., \& Levi, L. (2003). Thinking mathematically: Integrating arithmetic and algebra in elementary school. Heinemann, 361 Hanover Street, Portsmouth, NH.

Chazan, D. (1993). High school geometry students' justification for their views of empirical evidence and mathematical proof. Educational studies in mathematics, 24(4), 359-387. https:/ / doi.org/10.1007/BF01273371

Dubinsky, E. (1986). Teaching mathematical induction I. Journal of Mathematical Behavior, 5, 305-317.

Dubinsky, E. (1990). Teaching mathematical induction II. Journal of Mathematical Behavior, 8, 285-304.

Dubinsky, E., \& Lewin, P. (1986). Reflective abstraction and mathematics education: The generic decomposition of induction and compactness. Journal of Mathematical Behavior, 5, 55-92.

Ellis, A. B. (2011). Generalizing-promoting actions: How classroom collaborations can support students' mathematical generalizations. Journal for Research in Mathematics Education, 42(4), 308-345. https://doi.org/10.5951/jresematheduc.42.4.0308

Hanna, G. (1991). Mathematical proof. In D. Tall (Ed.), Advanced mathematical thinking (pp. 54-61). Dordrech, The Netherlands: Kluwer Academic Publishers.

Hanna, G. (1995). Challenges to the importance of proof. For the Learning of Mathematics, 15, 42-49.

Harel, G. (2002). The development of mathematical induction as a proof scheme: A model for DNR-based instruction. In S. Campbell, \& R. Zaskis (Eds.), Learning and teaching number theory: Research in cognition and instruction (pp. 185-212). New Jersey: Ablex Publishing Corporation.

Herbst, P. G. (2002). Engaging students in proving: A double bind on the teacher. Journal for research in mathematics education, 176-203. https: / / doi.org/10.2307/749724

Herbst, P., \& Brach, C. (2006). Proving and doing proofs in high school geometry classes: What is it that is going on for students? Cognition and Instruction, 24(1), 73-122. https:/ / doi.org/10.1207/s1532690xci2401_2

Piaget, J., \& Inhelder, B. (2013). The growth of logical thinking from childhood to adolescence: An essay on the construction of formal operational structures. Routledge. https://doi.org/10.4324/9781315009674

Jeannotte, D., \& Kieran, C. (2017). A conceptual model of mathematical reasoning for school mathematics. Educational Studies in Mathematics, 96(1), 1-16. https:/ / doi.org/10.1007/s10649-017-9761-8

Kilpatrick, J., Swafford, J., \& Findell, B. (2001). The strands of mathematical proficiency. Adding it up: Helping children learn mathematics, 115-118.

Knuth, E. J. (2002). Secondary school mathematics teachers' conceptions of proof. Journal for Research in Mathematics Education, 33, 379-405. https://doi.org/10.2307/4149959

Lakatos, I. (1976). Proofs and refutations: The logic of mathematical discovery. Cambridge, UK: Cambridge University Press. https:// doi.org/10.1017/CBO9781139171472

Lehrer, R., \& Lesh, R. (2003). Mathematical learning. Handbook of psychology. https://doi.org/10.1002/0471264385.wei0715 
Lehrer, R., Kobiela, M., \& Weinberg, P. J. (2013). Cultivating inquiry about space in a middle school mathematics classroom. ZDM, 45(3), 365-376.

Movshovitz-Hadar, N. (1993). The false coin problem, mathematical induction and knowledge fragility. Journal of Mathematical Behavior, 12, 253-268.

National Council of Teachers of Mathematics (NCTM) (2000). Principles and Standards for School Mathematics, Commission on Standards for School Mathematics, Reston, VA: NCTM.

National Council of Teachers of Mathematics (NCTM) (1989). Curriculum and evaluation standards for school mathematics. Reston, VA: Author.

National Governors Association Center for Best Practices \& Council of Chief State School Officers. (2010). Common core state standards for mathematics. Washington, DC: Authors. Retrieved from http://www.corestandards.org/assets/CCSSI_Math\%20Standards.pdf

Piaget, J., \& Inhelder, B. (1958). The growth of logical thinking from childhood to adolescence. Cambridge, MA: Routledge.

Selden, J., \& Selden, A. (1995). Unpacking the logic of mathematical statements. Educational Studies in Mathematics, 29(2), 123-151. https:/ / doi.org/10.1007/BF01274210

Selden, A., \& Selden, J. (2013). Proof and problem solving at university level. The Mathematics Enthusiast, 10(1/2), 303.

Schauble, L. (1996). The development of scientific reasoning in knowledge-rich contexts. Developmental Psychology, 32(1), 102. https:/ / doi.org/10.1037/0012-1649.32.1.102

Schauble, L., Glaser, R., Duschl, R. A., Schulze, S., \& John, J. (1995). Students' understanding of the objectives and procedures of experimentation in the science classroom. The journal of the Learning Sciences, 4(2), 131-166. https:/ / doi.org/10.1207/s15327809j1s0402_1

Stylianides, A. J. (2007a). Introducing young children to the role of assumptions in proving. Mathematical Thinking and Learning, 9(4), 361-385. https:/ / doi.org/10.1080/10986060701533805

Stylianides, A. (2007b). Proof and proving in school mathematics. Journal for Research in Mathematics Education, 38(3), 289-321.

Stylianides, A. J. (2007c). The notion of proof in the context of elementary school mathematics. Educational Studies in Mathematics, 65, 1-20. https:/ / doi.org/10.1007/s10649-006-9038-0

Stylianides, A. J., \& Ball, D. L. (2008). Understanding and describing mathematical knowledge for teaching: Knowledge about proof for engaging students in the activity of proving. Journal of mathematics teacher education, 11(4), 307-332. https:/ / doi.org/10.1007/s10857-008-9077-9

Stylianides, G. J., \& Stylianides, A. J. (2009). Facilitating the transition from empirical arguments to proof. Journal for Research in Mathematics Education, 314-352.

Stylianides, G. J., Stylianides, A. J., \& Philippou, G. N. (2007). Preservice teachers' knowledge of proof by mathematical induction. Journal of Mathematics Teacher Education, 10(3), 145-166. https:/ / doi.org/10.1007/s10857-007-9034-z

van Hiele, P. M. (1986). Structure and insight: A theory of mathematics education. Academic Press.

Ward, S. L., \& Overton, W. F. (1990). Semantic familiarity, relevance, and the development of deductive reasoning. Developmental Psychology, 26(3), 488. https:/ / doi.org/10.1037/0012-1649.26.3.488

Zazkis, R. (2005). Representing numbers: Prime and irrational. International Journal of Mathematical Education in Science and Technology, 36(2-3), 207-217. https:// doi.org/10.1080/00207390412331316951

Zazkis, R., \& Sirotic, N. (2004). Making Sense of Irrational Numbers: Focusing on Representation. International Group for the Psychology of Mathematics Education. 


\section{APPENDIX A}

\section{Survey}

1. What is the purpose of proving in mathematics?

2. What different ideas might students have about what it means for something to be true for all cases in mathematics?

3. Give an example of how proof/proving is used in a mathematics course you teach/taught/took?

\section{APPENDIX B}

\section{Sample Mathematical Problems}

1. Consider $\frac{1}{3}$, which can be written as the following repeating decimal $0 . \overline{3}=0.33333 \ldots$ Explain why this decimal repeats.

2. How do you know whether a decimal will repeat or terminate? For example, $\frac{1}{6}$ compared with $\frac{3}{4}$.

3. Consider the number $0 . \overline{1}$. How would you characterize this number? Why does this decimal repeat? What can you say about $0 . \overline{01}$ ? What about $0.2 \overline{3}$ ? Explain your answer.

4. $\frac{1}{7}$ can be written as a repeating decimal. Paul says that there are a maximum of 6 decimal places that will repeat. Jaimie says that there is an unlimited amount of decimals that can repeat. What do you think? Why?

5. Consider $\frac{53}{83}$. In performing this division, the calculator display shows 0.63855421687 . Is this a rational or an irrational number? Explain.

6. Pi can be expressed as the infinite sums and differences of rational numbers (see below). Why then is it not considered a rational number?

$$
\pi=\frac{4}{1}-\frac{4}{3}+\frac{4}{5}-\frac{4}{7}+\frac{4}{9}-\frac{4}{11}+\frac{4}{13}-\cdots
$$

7. How would you characterize $3 \sqrt{8}$ ? Is $3 \sqrt{8}$ a rational, irrational, real, and/or complex number? How do you know?

8. Why is $\sqrt{2} \times \sqrt{3}=\sqrt{6}$ ? (Write down the rule they state) Is $\sqrt{6}$ rational or irrational? Why?

9. Is every irrational number times another irrational number an irrational number? Why is this the case? Is this true of irrational numbers plus other irrational numbers?

10. Consider the following number $0.12122122212 \ldots$ (there is an infinite number of digits where the number of 2 's between the 1's keeps increasing by one). Is this a rational or irrational number? How do you know?

11. What is the difference between a number like $\frac{1}{2}$ and a number like $\sqrt{2}$ ?

12. Between 0 and 1 are there more rational or irrational numbers? Why do you think so?

13. If I selected, at random, a point on the real number line, would I most likely pick a natural number, integer, irrational number, or rational number? Why do you think so? 


\section{APPENDIX C}

\section{Coding Scheme for Survey Responses}

\begin{tabular}{|c|c|c|}
\hline Coding Category & Definition & Example \\
\hline Does not address ideas in proving. & $\begin{array}{l}\text { Participant does not identify } \\
\text { any constituent practices } \\
\text { within proving (i.e. } \\
\text { generalizing, thinking about } \\
\text { bigger mathematical ideas) }\end{array}$ & $\begin{array}{l}\text { What is the purpose of proving in } \\
\text { mathematics? } \\
\text { "To check your work." } \\
\text { "To answer the question that is being } \\
\text { asked." }\end{array}$ \\
\hline Proving for a single example(s). & $\begin{array}{l}\text { Participant indicates proving } \\
\text { provides justification for only a } \\
\text { limited number of cases. }\end{array}$ & $\begin{array}{l}\text { "Proving is pretty much experimentation } \\
\text { in that a proof must explain why the } \\
\text { answer is what it is." } \\
\text { "For instance, triangle congruency } \\
\text { conjectures show you whether one } \\
\text { triangle is right." } \\
\text { "To show how you arrive at the correct } \\
\text { answer. Proofs are like detailed } \\
\text { examples." }\end{array}$ \\
\hline Proving based on a single example. & $\begin{array}{l}\text { Participant explains a class or } \\
\text { property of a class by citing a } \\
\text { limited number of examples. }\end{array}$ & $\begin{array}{l}\text { "Proving is the logical progression of } \\
\text { thinking in order to reinforce a theory } \\
\text { with hard evidence and data." } \\
\text { "Empirical data can prove something is } \\
\text { true in math just like in science." } \\
\text { "Proof allows you to know things by } \\
\text { identifying a trend." }\end{array}$ \\
\hline $\begin{array}{l}\text { Proving a mathematical question for } \\
\text { all cases. }\end{array}$ & $\begin{array}{l}\text { Participant explains a class or } \\
\text { property of a class (of } \\
\text { mathematical objects) by citing } \\
\text { properties or the relations } \\
\text { between general properties, } \\
\text { disconnected from the original } \\
\text { context that explicitly } \\
\text { represents this property. }\end{array}$ & $\begin{array}{l}\text { "...to prove that what you say is right by } \\
\text { basing it off of the ideas in other widely } \\
\text { accepted mathematics concepts." } \\
\text { "Proof allows you to know something is } \\
\text { true for all cases." } \\
\text { "Proving something demonstrates that it } \\
\text { will always be true." }\end{array}$ \\
\hline
\end{tabular}




\section{APPENDIX D}

\section{Problem-solving Session Coding Scheme}

\begin{tabular}{ll}
\hline Categories & Levels \\
\hline Generalization & a. No Generalization \\
& b. Implicit generalization
\end{tabular}

Participant refers to a specific "The $\sqrt{2}$ is equal to $1.414 \ldots$ ".

mathematical object,

measure, property, or

computational product.

Participant refers to a specific "Numbers like $\sqrt{2}$ do not terminate or mathematical object, measure repeat."

or property, but implicitly

represents or easily affords a

generalization.

c. Explicit generalization

Explicit reference to a mathematical class, such as 'irrational numbers,' or to a property of a class, such as the 'area of triangles.'

a. No proving

Participant refers to a

"All irrational numbers do not terminate or repeat." mathematical object, measure, property, or computational product.

b. Naïve empiricism

Participant asserts the " $2^{2} 2^{5}$ is 128 because $2^{2}=4$ and $2^{5}=$ validity of a mathematical $\quad 32$ so $4 \times 32=128$. So, you can always result after confirming a finite add the exponents to get the right number of cases answer."

c. Generic example

Participant makes explicit the reasons for the truth of a mathematical assertion by means of operations or transformations on an object that is not there in its own right, but as a characteristic representative of its class.

$2^{2} 2^{5}$ is 128 because $2^{2}$
32 so $4 \times 32=128 . "$

" $2^{2}=2 \times 2$ and $2^{5}=2 \times 2 \times 2 \times 2 \times 2$ so we can write the product of those as $2 \times 2 \times 2 \times 2 \times 2 \times 2 \times 2$ which we symbolize as $2^{7}$...Because $a^{b} \times a^{c}=$ $a^{b+c}$

(b,c are integers) since $a^{b}$ means to multiply $a$ by itself $b$ times and $a^{c}$ means to multiply $a$ by itself $c$."

d. Thought experiment

Participant indicates a " $2^{2}=2 \times 2$ and $2^{5}=2 \times 2 \times 2 \times 2 \times$ generic example. In addition, $2 \ldots$ so, we can write the product of participant constructs an anecdotal temporal those as $2 \times 2 \times 2 \times 2 \times 2 \times 2 \times 2$ which we symbolize as $2^{7}$...Accordingly, for development, where the any $a \in \mathbb{R}$ and any $m \in \mathbb{N}$, the statement mathematical operations and $P(n)=a^{m} \times a^{n}=a^{m+n}$, for all $n \in$ foundational relations are $\quad \mathbb{N}, P(n)$ is true. For $n=1, P(n)$ is true indicated in some other way since by definition, $a^{m} a^{1}=a^{m} a=$ than by the result of their use. $a^{m+1}$. Now suppose that for some $n=$ $k, P(n)$ is true, $a^{m} a^{k}=a^{m+k}$. Then $a^{m} a^{k+1}=\left(a^{m} a^{k}\right) a=a^{m+k} a=$ $a^{(m+k)+1}=a^{m+(k+1)}$. Thus, $P(n) \Rightarrow$ $P(n+1)$, and since $P(1)$ is true, $\mathrm{P}(\mathrm{n})$ is true for all $n \in \mathbb{N}$.

\section{http://www.ejmste.com}

